\title{
Modeling of chemical inhibition from amyloid protein aggregation kinetics
}

José Antonio Vázquez

\begin{abstract}
Backgrounds: The process of amyloid proteins aggregation causes several human neuropathologies. In some cases, e.g. fibrillar deposits of insulin, the problems are generated in the processes of production and purification of protein and in the pump devices or injectable preparations for diabetics. Experimental kinetics and adequate modelling of chemical inhibition from amyloid aggregation are of practical importance in order to study the viable processing, formulation and storage as well as to predict and optimize the best conditions to reduce the effect of protein nucleation.

Results: In this manuscript, experimental data of insulin, A 42 amyloid protein and apomyoglobin fibrillation from recent bibliography were selected to evaluate the capability of a bivariate sigmoid equation to model them. The mathematical functions (logistic combined with Weibull equation) were used in reparameterized form and the effect of inhibitor concentrations on kinetic parameters from logistic equation were perfectly defined and explained. The surfaces of data were accurately described by proposed model and the presented analysis characterized the inhibitory influence on the protein aggregation by several chemicals. Discrimination between true and apparent inhibitors was also confirmed by the bivariate equation. EGCG for insulin (working at $\mathrm{pH}=7.4 / \mathrm{T}=37^{\circ} \mathrm{C}$ ) and taiwaniaflavone for $A \beta 42$ were the compounds studied that shown the greatest inhibition capacity.

Conclusions: An accurate, simple and effective model to investigate the inhibition of chemicals on amyloid protein aggregation has been developed. The equation could be useful for the clear quantification of inhibitor potential of chemicals and rigorous comparison among them.
\end{abstract}

Keywords: Protein fibrillation kinetics, Mathematical modeling, Sigmoid bivariate equation

\section{Background}

The aggregation and fibrillation of proteins has been commonly associated with numerous degenerative disorders in humans including Alzheimer's, Parkinson's, prion's, diabetes type II and Huntington's diseases [1-5]. These proteins, called amylodogenics, are also involved in production, purification and formulation interferences of biotechnology and pharmacologic processes [6,7]. The phenomenon of protein aggregation, led by nucleationdependent polymerization mechanism, consists in the formation of amyloid fibrils formulated with $\beta$-sheet structures in cross- $\beta$-sheet arrangement producing insoluble aggregates [8-10]. For example, insulin peptide also generates fibrillar structures under specific conditions such as low $\mathrm{pH}$, high temperatures or organic solvents

Correspondence: jvazquez@iim.csic.es

Grupo de Reciclado e Valorización de Residuos (REVAL), Instituto de Investigacións Mariñas (IIM-CSIC), C/ Eduardo Cabello 6, CP36208 Vigo, Spain dilution [11-13]. Those phase transformations are not observed in vivo but are very common, for example, in the clinical preparations of insulin for diabetics [14]. Human amyloid proteins $(A \beta)$ are peptides of rather 3942 residues. $A \beta 40$ contains 40 amino acids and $A \beta 42$ is the major isoform in the $\mathrm{A} \beta$ peptides with 42 residues polypeptide chain and it is the responsible of amyloid plaques generated in Alzheimer's disorder $[15,16]$.

In general, much of the success in the future application of chemicals to inhibit the in vivo formation of such fibrils is dependent on the correct modelling and evaluation of in vitro kinetic data in order to establish protocols of action, effectiveness of molecules and dose-optimization of compounds. The kinetic description of amyloid protein aggregation based on mechanistic and thermodynamic approaches have been extensively studied [17-22] and an ample number of plausible mechanisms of nucleation and fibrillation have been proposed [23,24]. So remarkable, 
two new and similar proposal: "Ockham's razor"/minimalistic and Crystallization-like Model, have been recently developed. Both have solid biophysical basis and they were successfully applied to describe and explain the experimental data of different amyloid protein aggregation [25-28]. However, the combined effect of antiaggregation protein agents, e.g. surfactants, osmolytes and food additives, on time-dependent responses has not been modelled by that way or by means of empirical equations.

Although the use of empirical sigmoid equations, mainly the logistic equation, does not provide a direct explanation of the molecular steps that underlie in the generation of fibrils, it is a robust tool to examine protein aggregation kinetic data and to address all the phases of the process $[4,29,30]$. In addition, other authors assimilated the parameters from logistic [20] to those obtained by an autocatalytic mechanism [23,27]. Nonetheless, that equation is always formulated without the parameters (fibrillation rate and lag phase) in an explicit form hindering the estimation of their statistical error.

In the present work, the capability of fit and experimental data predictability of a sigmoid bivariate model that simulates the growth of aggregation process on different proteins along with the effects of inhibitory chemicals on the kinetic parameters is explored in selected cases obtained from the literature. The results reveal its efficacy and validity to analyze the most relevant parameters that describe geometrically and macroscopically the mentioned process.

\section{Methods}

\section{Experimental data}

Amyloid protein aggregation data were collected from results previously reported in the bibliography and digitized from the published curves using GetData Graph Digitizer 2.24. The kinetics of insulin inhibition induced by (-)-epigallocatechin-3-gallate (EGCG) were selected from Wang et al. [31], methylglyoxal effects were collected from Oliveira et al. [32] and those produced by 1,2-diheptanoyl-sn-glycero-3-phosphocholine (di-C7-PC) were described in Wang et al. [33]. Two conditions of EGCG affecting to fibrillation kinetics were used: EGCG_1 (case 1) studied at $\mathrm{pH}=2.0 / \mathrm{T}=60^{\circ} \mathrm{C}$ and EGCG_2 (case 2) at $\mathrm{pH}=7.4 / \mathrm{T}=37^{\circ} \mathrm{C}$.

On the other hand, the aggregation kinetics of $\mathrm{A} \beta 42$ amyloid protein inhibited by apigenin and taiwaniaflavone were selected from Thapa et al. [16] and the data affected by ectoine and hydroxyectoine from Kanapathipillai et al. [15]. Finally, apomyoglobin fibrillation experiments were published in Vilasi et al. [34]. The datasets were obtained by the two most common methods used to probe amyloid formation in vitro, the increment in light scattering of the protein solution due to insolubilization, and the increase in ThT fluorescence due to amyloid binding.

\section{Mathematical modelling}

The model developed to simulate the process of aggregation and hence insulin fibrillation was defined by a bivariate equation. Such model is based on the combination of Weibull function as chemical-concentration model $[35,36]$ modifying the most important parameters of the reparameterized logistic equation [37] used for aggregation description. This expression (1) has been successfully used, in recent works, to evaluate the inhibitory effect of organic acids and heavy metals on the growth of various bacteria $[38,39]$. Its mathematical form is as follows (see also Appendix section):

$$
\begin{aligned}
& X=\frac{X_{m}}{1+\exp \left[2+\frac{4 v_{m} \cdot}{X_{m}}\left(\lambda_{\bullet}-t\right)\right]} ; \text { where }: \\
& X_{m \bullet}=X_{m}\left\{1-K_{x}\left[1-\exp \left(-\ln 2\left(\frac{C}{m_{x}}\right)^{a_{x}}\right)\right]\right\} \\
& v_{m_{\bullet}}=v_{m}\left\{1-K_{v}\left[1-\exp \left(-\ln 2\left(\frac{C}{m_{v}}\right)^{a_{\nu}}\right)\right]\right\} \\
& \lambda \cdot=\lambda\left\{1+K_{\lambda}\left[1-\exp \left(-\ln 2\left(\frac{C}{m_{\lambda}}\right)^{a_{\lambda}}\right)\right]\right\}
\end{aligned}
$$

where, $v_{m}$ is the maximum aggregation rate, $X_{m}$ is the maximum aggregation growth, $\lambda$ is the lag phase and $C$ is the chemical concentration. The meanings of other symbolic notations as well as the corresponding units are summarized in Table 1 . In the experimental data chosen, the dependent variable of response or timedependent signals $(X)$ to detect amyloid protein aggregation were absorbance at $600 \mathrm{~nm}$ (data obtained from Wang et al. [31]), relative ThT fluorescence intensity (\%) (data from Wang et al. [33]) and ThT fluorescence intensity at $482 \mathrm{~nm}$ or $490 \mathrm{~nm}$ (data obtained from Thapa et al. [16]; Kanapathipillaia et al. [15]; Oliveira et al. [32] and Vilasi et al. [34]).

Additionally, a global parameter $\left(E C_{50, \tau}\right)$ was also selected for the overall description of chemical effects on fibrillation growth studies according the algebraic steps previously described [38]. This parameter was defined as the chemical concentration (in $\mathrm{mM}$ ) that reduces the aggregation by $50 \%$ compared to that produced by the control without agent at time $(\tau)$ which also reduces the maximum aggregation by $50 \%$.

\section{Numerical methods and statistical analysis}

The fitting procedures and parametric estimates from the experimental results were performed by minimizing the sum of quadratic differences between the observed and model-predicted values using the nonlinear least- 
Table 1 Symbolic notations used and corresponding units

\begin{tabular}{|c|c|}
\hline \multicolumn{2}{|c|}{$\begin{array}{l}\text { Insulin aggregation kinetics measured by } \\
\text { absorbance or fluorescence }\end{array}$} \\
\hline$x:$ & $\begin{array}{l}\text { Amyloid aggregation growth measured as absorbance at } 600 \mathrm{~nm} \text {, relative ThT fluorescence intensity } \\
\text { (\%) and ThT fluorescence intensity at } 482 \mathrm{~nm} \text { or } 490 \mathrm{~nm} \text {. Units: absorbance units (AU) or (\%). }\end{array}$ \\
\hline$t:$ & Time. Units: $h$ or d \\
\hline$X_{m}:$ & Maximum aggregation growth. Units: AU or \% \\
\hline$v_{m}:$ & Maximum aggregation rate. Units: $\mathrm{AU} \mathrm{h}^{-1}, \mathrm{AU} \mathrm{d}^{-1}$ or $\% \mathrm{~h}^{-1}$ \\
\hline$\lambda:$ & Lag phase. Units: h or d \\
\hline$x_{m} \cdot$ & Maximum insulin aggregation affected by chemical agent. Units: AU or \% \\
\hline$v_{m} \cdot:$ & Maximum insulin aggregation rate affected by chemical agent. Units: $A \cup h^{-1}, A U d^{-1}$ or $\% h^{-1}$ \\
\hline$\lambda \bullet:$ & Lag phase affected by chemical agent. Units: h or d \\
\hline \multicolumn{2}{|c|}{ Concentration effects on insulin aggregation kinetics } \\
\hline$C:$ & Concentration of chemical agent. Units: $\mathrm{mM}$ or $\mu \mathrm{M}$ \\
\hline$K_{x}:$ & Maximum response affecting on $X_{m}$. Dimensionless \\
\hline$m_{x}:$ & Concentration corresponding to the semi-maximum response affecting on $X_{m}$. Units: $\mathrm{mM}$ or $\mu \mathrm{M}$ \\
\hline$a_{x}:$ & Shape parameter affecting on $X_{m}$. Dimensionless \\
\hline$K_{v}:$ & Maximum response affecting on $v_{m}$. Dimensionless \\
\hline$m_{v}:$ & Concentration corresponding to the semi-maximum response affecting on $v_{m}$. Units: $\mathrm{mM}$ or $\mu \mathrm{M}$ \\
\hline$a_{v}:$ & Shape parameter affecting on $v_{m}$. Dimensionless \\
\hline$K_{\lambda}:$ & Maximum response affecting on $\lambda$. Dimensionless \\
\hline$m_{\lambda}:$ & Concentration corresponding to the semi-maximum response affecting on $\lambda$. Units: $\mathrm{mM}$ or $\mu \mathrm{M}$ \\
\hline$a_{\lambda}:$ & Shape parameter affecting on $\lambda$. Dimensionless \\
\hline
\end{tabular}

squares (quasi-Newton) method provided by the 'Solver' macro from Microsoft Excel spreadsheet. The confidence intervals of the best-fit values for the parametric estimates (Student's $\mathrm{t}$ test, $\alpha=0.05$ ), consistency of the mathematical models (Fisher's F test; $p<0.05$ ) and covariance and correlation matrices were calculated using the 'SolverAid' macro, which is freely available from Levie's Excellaneous website http://www.bowdoin.edu/ rdelevie/ exellaneous/. An example of the type of Excel spreadsheet used for modeling (Ab42amyloid apigenin case) was provided as Additional file 1. These statistical procedures and residual analysis (Durbin-Watson test) were confirmed and evaluated, respectively, by DataFit 9 (Oakdale Engineering, Oakdale, PA). Moreover, bias and accuracy factors of fittings ( $B_{f}$ and $A_{f}$ respectively) were calculated according to the expressions reported by Ross [40].

\section{Results and discussion}

\section{Characteristics and simulations of bivariate model}

In the description of amyloidogenic fibrillation growths, the logistic equation used to formalize their kinetic profiles is always formulated through an explicit expression based on the time required to reach $50 \%$ of the maximal aggregation $\left(x_{0}\right)$ and a time parameter $(\tau)$, although the initial lag phase and the aggregation rate are commonly the most important parameters that need to be calculated [30]. In this work, the logistic equation was reparameterized to make the lag phase $(\lambda)$ and the maximum aggregation rate $\left(v_{m}\right)$, which represents the overall aggregation process rate, explicit (Figure 1). This last coefficient more adequately characterizes the reaction rate of fibrillation than the parameter conventionally used ( $k_{\text {app }}$, defined as specific or apparent rate) because it is less sensitive to experimental error and because it is a more efficient to describe the global rate of the kinetic process [41]. Additionally, the $v_{m}$ calculated from the experimental data obtained by Sabaté et al. [42] for yeast prion proteins follows the Arrhenius dependence with temperature (data not shown).

In contrast, the fit using the reparameterized functions can be used to easily calculate the confidence intervals of the parameters. The algebraic steps required to obtain the corresponding reparameterization of $\lambda$ and $v_{m}$ from the logistic equation are detailed in the Appendix. Thus, the parameters from this equation define all of the aggregation kinetic phases [19]: pre-nucleation, which is characterized by $\lambda$, post-nucleation, which is represented by $v_{m}$ or $\mathrm{\tau}$, and elongation, which is determined by $X_{m}$.

The absolute correlation between the lag phase and the aggregation growth was recently demonstrated in several sets of protein data [43]. Indeed, this relationship is obvious because the specific or apparent rate $\left(k_{a p p}\right.$ or $k_{g}$, depending on the authors) is inversely proportional to the lag phase based the following expression when the logistic model (1) is applied [44]: 

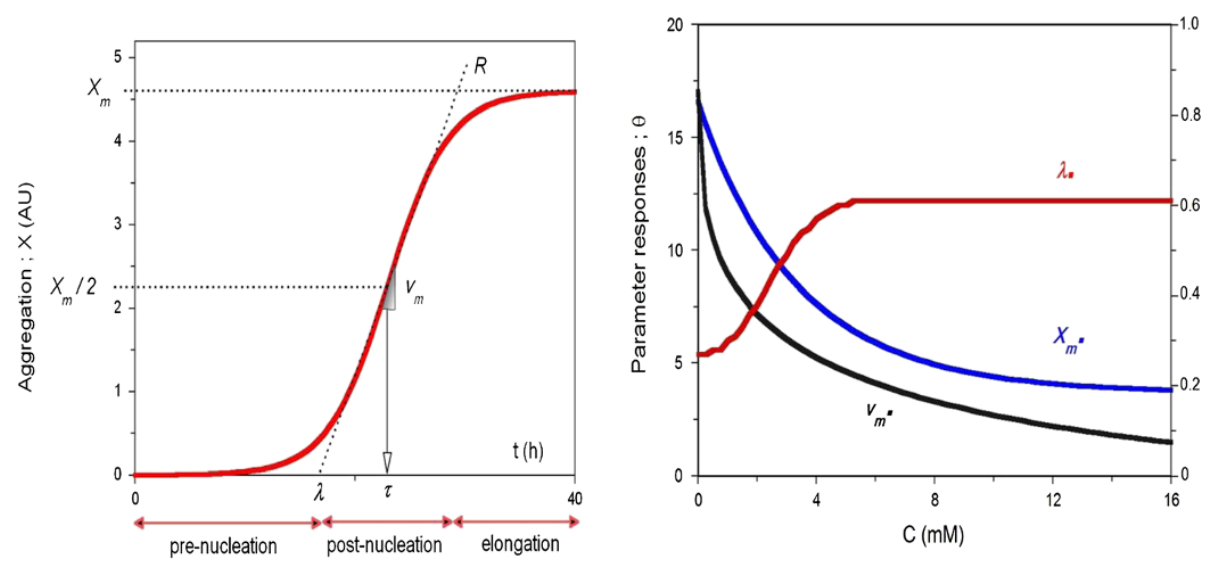

Figure 1 Left, Graphical description of the kinetic parameters $\left(X_{m}, \lambda, v_{m}\right.$ and $\left.\tau\right)$ from the logistic equation (A.8) and the corresponding aggregation phases: pre-nucleation, post-nucleation and elongation. Right, Simulations of the most common profiles for the parameters $\left(X_{m} \cdot \lambda_{\bullet}, V_{m} \cdot\right)$, affected by chemical concentration, using the Weibull equations (A.15).

$$
\lambda=\tau-\frac{2}{k_{a p p}}
$$

Figure 2 shows an illustrative set of simulations that were developed under the numerical conditions described in Table 2. In these simulations, all of the possible sigmoid effects of the chemical concentration on the logistic parameters are defined. Weibull's equation, which was adequately configured to simulate the doseresponse trends, is a mathematical tool that provides excellent predictions for varied experimental profiles from different scientific fields $[45,46]$. In the present context, the flexibility of this equation to describe different chemical-concentration relationships as linear, sigmoid, exponential, or hyperbolic curves depending on the numerical values of the parameters is particularly valuable. The combination of both of these mathematical resources (1) generates a wide variety of theoretical casuistries that will be verified using the experimental data selected below.

\section{Inhibitory effect of EGCG on insulin aggregation}

The representation of the experimental data from selected cases and surfaces predicted by equation (1) are depicted in Figure 3A and B. The results of the parameter estimations and the statistical analysis of the fit for the EGCG influence on insulin fibrillation are summarized in Table 3. Both datasets were accurately fitted with equation (1) to obtain $R_{a d j}^{2}$ values greater than 0.98 . Moreover, the $p$-values obtained from Fisher's $\mathrm{F}$ test indicated the complete consistency and robustness of the equation to the adjustment of the experimental patterns. The residual analysis through the Durbin-Watson test revealed a lack of residual autocorrelation and therefore a random distribution (data not shown).
At an acidic $\mathrm{pH}$ and a high temperature, the effect of EGCG on the kinetic parameters was not significant for the maximum aggregation rate but statistically significant for $X_{m}$ and the lag phase. As can be observed in Figure $3 \mathrm{~A}$, the slopes of the sigmoid curves were parallel to the influence of the EGCG concentration, and the surface can be assimilated to that simulated in Figure 2D but with less effect on $X_{m}$. These results show a longer pre-nucleation phase, which indicates that EGCG blocks the formation of the seeding nuclei without changing the fibril elongation rate (post-nucleation). This behaviour is consistent with the definition reported by Martins [26] who denominates the compounds that modify kinetic parameters (for instance in the present case, $v_{m}$ and/ or $\lambda$ ) as true inhibitors.

In contrast, different surface and parametric responses were observed for EGCG_2 up to a concentration of 0.2 $\mathrm{mM}$ polyphenol with only significant modifications in the maximum aggregation growth parameter (Figure 3B). Under experimental conditions of higher $\mathrm{pH}$ and lower T, EGCG acts as an apparent inhibitor that only alters the thermodynamic properties of aggregation process [26]. Higher concentrations of EGCG (from 0.35 to 0.7 $\mathrm{mM}$ ) led to an increase in the fibrillation response more than the inhibition of the amyloid process [31]. These experimental points were deleted in this mathematical analysis because biphasic aggregation data with profiles of decreasing and increasing values of $X_{m}$ cannot be fitted by the proposed equation or by any other simple equation.

The global description of chemical inhibition was calculated by means of a single index: $E C_{50, \tau}$ (Table 3 ). This parameter can be defined as a summary of all of the effects on the aggregation kinetics observed at the time required to reach the semi-maximum aggregation growth. Thus, the obtained value of this parameter can be used 


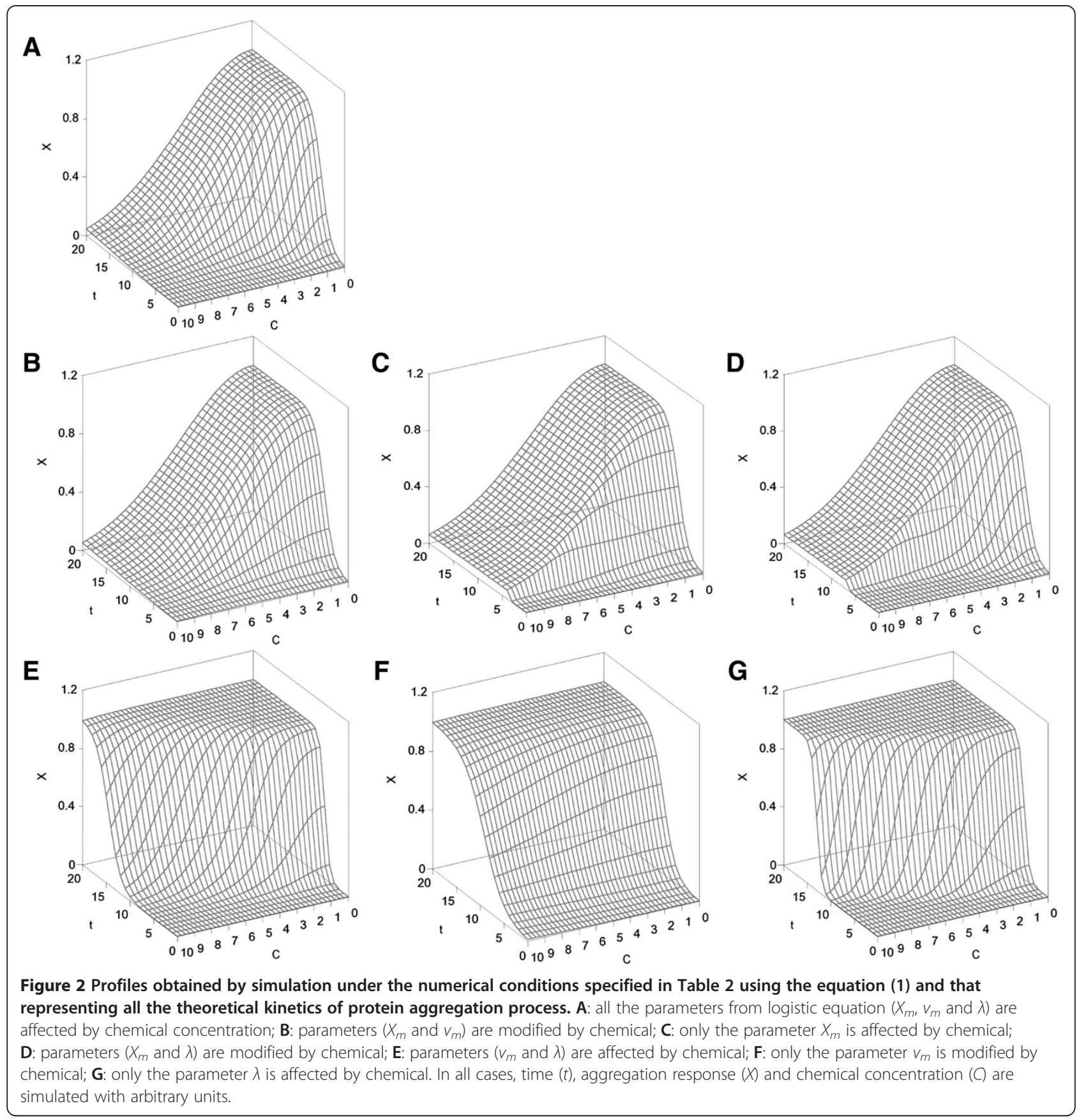

for the comparison and the evaluation of the application of chemicals to reduce the protein fibrillation. The results demonstrated that the most inhibitory conditions for EGCG are established at neutral $\mathrm{pH}$ and a lower temperature (case 2), but these conditions require a longer time $(\tau)$ to achieve the parameter $E C_{50, \tau}$.

\section{Inhibitory effect of di-C7-PC and methylglyoxal on insulin aggregation}

Figure $3 \mathrm{C}$ displays the surface described by equation (1) and data on the insulin kinetics in the presence of a surfactant. The parameter values and the statistical characteristics of the modeling were also determined (Table 3). All of the statistical results revealed good agreement and accuracy between the observed and the predicted values, the consistency of the equation, and a lack of bias during the fitting process.

Regarding the effects, the two kinetic parameters $v_{m}$ and $X_{m}$ were significantly affected by di-C7-PC, whereas the lag phase was not modified by the surfactant (Student's $\mathrm{t}$ test, $\alpha=0.05$ ), as determined in the simulated conditions defined by Figure 2B. This result is in agreement with data 
Table 2 Arbitrary numerical values defined for the simulations of Figure $\mathbf{1}$ (A, B, C, D, E, F and G) according to the parameters defined in the equation (1)

\begin{tabular}{lcccccccc}
\hline & & \multicolumn{7}{c}{ Simulation conditions } \\
\cline { 2 - 9 } Parameters & & $\mathbf{A}$ & $\mathbf{B}$ & $\mathbf{C}$ & $\mathbf{D}$ & $\mathbf{E}$ & $\mathbf{F}$ & $\mathbf{G}$ \\
\hline Aggregation growth & $X_{m}$ & 1.00 & 1.00 & 1.00 & 1.00 & 1.00 & 1.00 & 1.00 \\
& $V_{m}$ & 0.25 & 0.25 & 0.25 & 0.25 & 0.50 & 0.20 & 0.50 \\
& $\lambda$ & 3.00 & 3.00 & 3.00 & 3.00 & 4.00 & 5.00 & 4.00 \\
Effect on $X_{m}$ & $K_{x}$ & 1.00 & 1.00 & 1.00 & 1.00 & - & - & - \\
& $m_{x}$ & 5.00 & 5.00 & 5.00 & 5.00 & - & - & - \\
Effect on $v_{m}$ & $a_{x}$ & 2.00 & 2.00 & 2.00 & 2.00 & - & - & - \\
& $K_{v}$ & 1.00 & 1.00 & - & - & 0.60 & 0.60 & - \\
& $m_{v}$ & 4.00 & 4.00 & - & - & 3.00 & 8.00 & - \\
Effect on $\lambda$ & $a_{v}$ & 2.00 & 2.00 & - & - & 2.00 & 2.00 & - \\
& $K_{\lambda}$ & 1.00 & - & - & 1.00 & 4.00 & - & 4.00 \\
& $m_{\lambda}$ & 2.00 & - & - & 2.00 & 10.00 & - & 10.00 \\
& $a_{\lambda}$ & 2.00 & - & - & 2.00 & 2.00 & - & 2.00 \\
\hline
\end{tabular}

reported for different systems of effector/protein, such as copper/ $\beta$-amyloid [47] or glutathione/hen egg-white lysozyme, although these data were obtained using a nonmathematical approach [48]. The value of $E C_{50, \tau}$ was similar to that obtained for EGCG (case 1) for a lower initial concentration of insulin, but a much longer time was required to obtain this parametric value $(150.68 \mathrm{~h})$.

Similar inhibitory responses were also observed with methylglyoxal; thus, $v_{m}$ and $X_{m}$ were the kinetic parameters inhibited by this aldehyde form of pyruvic acid (Table 3 and Figure 3D). Under an initial insulin concentration $(3 \mathrm{~g} / \mathrm{L})$ that was higher than the initial EGCG concentration, methylglyoxal effectively reduced the aggregation growth $(0.33 \mathrm{mM})$ within a shorter time (3.9 h). Both chemicals (di-C7-PC and methylglyoxal), under the experimental conditions assayed, showed similar features of true inhibitors [26]. The application of the proposed methodology may help the design of optimal strategies for the reduction of the fibril deposition of insulin in commercial preparations.
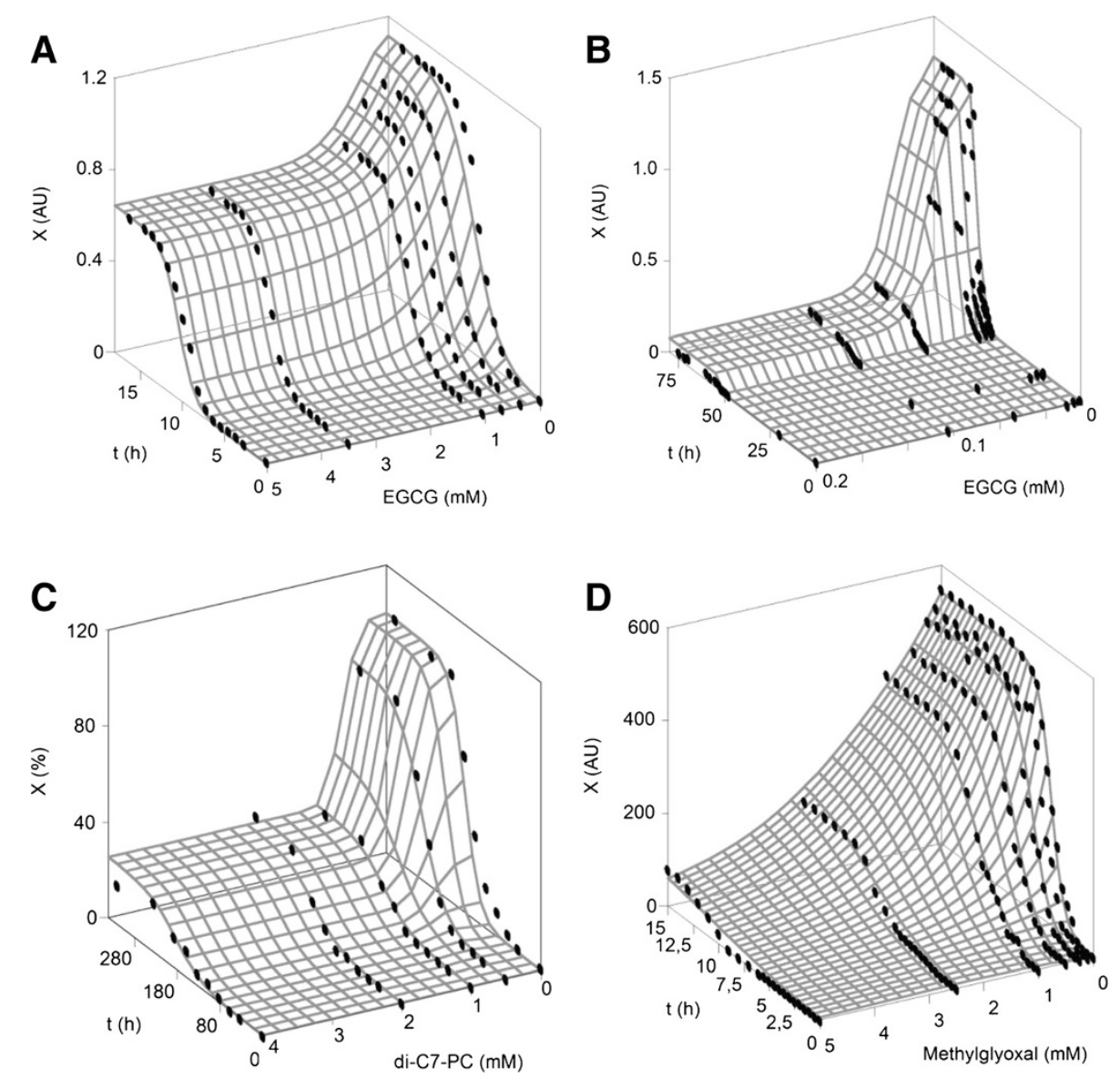

Figure 3 Insulin fibrillation kinetics at different concentrations of EGCG, di-C7-PC and methylglyoxal (points) and fittings to equation (1) (surface). X: aggregation data measured by absorbance at $600 \mathrm{~nm}$ (AU), ThT fluorescence intensity at $482 \mathrm{~nm}$ (AU) or ThT fluorescence intensity (\%). A: experimental data of EGCG obtained at $\mathrm{pH}=2.0$ and $\mathrm{T}=60^{\circ} \mathrm{C}$. B: experimental data of EGCG obtained at $\mathrm{pH}=7.4$ and $\mathrm{T}=37^{\circ} \mathrm{C}$. C: di-C7-PC data. D: methylglyoxal data. 
Table 3 Parametric estimates and confidence intervals $(\alpha=0.05)$ from the equation $(1)$ applied to the aggregation insulin increased data influenced by EGCG_1, EGCG_2, di-C7-PC and methylglyoxal concentrations

\begin{tabular}{|c|c|c|c|c|c|}
\hline \multicolumn{2}{|l|}{ Parameters } & \multirow{2}{*}{$\frac{\text { EGCG_1 }}{1.12 \pm 0.03}$} & \multirow{2}{*}{$\begin{array}{c}\text { EGCG_2 } \\
1.28 \pm 0.06\end{array}$} & \multirow{2}{*}{$\begin{array}{c}\text { di-C7-PC } \\
99.85 \pm 4.91\end{array}$} & \multirow{2}{*}{$\begin{array}{r}\text { Methylglyoxa } \\
541.20 \pm 11.38\end{array}$} \\
\hline Aggregation model & $X_{m}(\mathrm{AU}$ or $\%)$ & & & & \\
\hline & $v_{m}\left(\mathrm{AU} \mathrm{h}^{-1}\right.$ or $\left.\% \mathrm{~h}^{-1}\right)$ & $0.18 \pm 0.01$ & $0.25 \pm 0.04$ & $1.55 \pm 0.27$ & $219.68 \pm 20.98$ \\
\hline & $\lambda(h)$ & $4.78 \pm 0.28$ & $53.34 \pm 0.28$ & $124.62 \pm 5.86$ & $2.92 \pm 0.12$ \\
\hline \multirow[t]{3}{*}{ Effect on $X_{m}$} & $K_{x}$ & $0.43 \pm 0.03$ & $0.94 \pm 0.02$ & $0.75 \pm 0.05$ & $1.00 \pm 0.44$ \\
\hline & $m_{x}(\mathrm{mM})$ & $0.68 \pm 0.08$ & $0.01 \pm 0.00$ & $0.65 \pm 0.12$ & $1.80 \pm 1.25$ \\
\hline & $a_{x}$ & $1.65 \pm 0.45$ & $0.96 \pm 0.20$ & $4.04 \pm 2.37$ & $0.99 \pm 0.23$ \\
\hline \multirow[t]{3}{*}{ Effect on $v_{m}$} & $K_{v}$ & NS & NS & $0.86 \pm 0.04$ & $0.99 \pm 0.01$ \\
\hline & $m_{v}(\mathrm{mM})$ & NS & NS & $0.47 \pm 0.06$ & $0.42 \pm 0.07$ \\
\hline & $a_{v}$ & NS & NS & $2.51 \pm 2.35$ & $0.74 \pm 0.08$ \\
\hline \multirow[t]{9}{*}{ Effect on $\lambda$} & $K_{\lambda}$ & $0.81 \pm 0.10$ & NS & NS & NS \\
\hline & $m_{\lambda}(\mathrm{mM})$ & $0.50 \pm 0.08$ & NS & NS & NS \\
\hline & $a_{\lambda}$ & $0.98 \pm 0.24$ & NS & NS & NS \\
\hline & $E C_{50, \tau}(\mathrm{mM})$ & 0.44 & 0.006 & 0.47 & 0.33 \\
\hline & $\tau(h)$ & 7.65 & 55.02 & 150.68 & 3.92 \\
\hline & $p$-value & $<0.001$ & $<0.001$ & $<0.001$ & $<0.001$ \\
\hline & $B_{f}$ & 0.88 & 0.80 & 1.00 & 1.04 \\
\hline & $A_{f}$ & 1.23 & 1.40 & 1.18 & 1.15 \\
\hline & $R_{a d j}^{2}$ & 0.992 & 0.977 & 0.984 & 0.974 \\
\hline
\end{tabular}

Statistical values of adjusted coefficient of multiple determination $\left(R_{\text {adj }}^{2}\right)$ and $p$-values from Fisher's F-test $(\alpha=0.05) . B_{f}$ and $A_{f}$ are the bias and accuracy factor, respectively. NS: non-significant.

\section{Inhibitory effect of mono and biflavonoids on $A \beta 42$ amyloid protein}

The dependence of the kinetic parameters of fibrillation on the apigenin and taiwaniaflavone concentrations is represented in Figures $4 \mathrm{~A}$ and B. Both response surfaces were similar to that defined by the simulation shown in Figure 2A. The three parameters $\left(v_{m}, X_{m}\right.$, and $\left.\lambda\right)$ were clearly and significantly modified by these chemical doses (Table 4), which show a longer pre-nucleation phase, a lower elongation rate (post-nucleation), and a lower elongation stage. Such responses confirmed their chemical features of true inhibitors, being the only case in which both kinetic parameters $\left(v_{m}\right.$ and $\left.\lambda\right)$ significantly affected aggregation process [26]. All of the statistical tests corroborated the perfect agreement between the experimental and the theoretical data (e.g., $\left.R_{a d j}^{2}>0.99\right)$. The bias and accuracy factors $\left(B_{f}\right.$ and $\left.A_{f}\right)$ were also indicative of the good fitting quality obtained with model (1).

The numerical values of $E C_{50, \tau}$ confirmed the superior antifibrillogenic capacity of the biflavonoid taiwaniaflavone $\left(E C_{50, \tau}=0.91 \mu \mathrm{M}\right)$ compared with the monoflavonoid apigenin $\left(E C_{50, \tau}=2.45 \mu \mathrm{M}\right)$. However, the time $\tau$ was quite similar in both cases. This affirmation is consistent with the conclusions reported in the original work conducted by Thapa et al. [16].
Inhibitory effect of osmolytes on $A \beta 42$ amyloid protein Different types of molecules have been recently suggested as drug candidates for the treatment of neurodegenerative disorders caused by the anti-aggregation properties of amyloid proteins [49]. One of the most interesting candidates are osmolytes (compounds that protect against the osmotic stress), such as the ectoines that are obtained from aerobic heterotrophic bacteria [50]. The response surface for hydroxyectoine (Figure 4C) shows a behavior that is similar to that obtained with the simulation shown in Figure 2B. Based on the numerical fittings summarized in Table 4, it was statistically demonstrated that osmolytes inhibited the maximum aggregation rate and the maximum fibrillation growth. In contrast, no significant changes in the lag phase were observed. Therefore, both osmolytes effectively blocked the post-nucleation and the elongation stages but not the pre-nuclei formation. In addition, ectoine was much more effective as an antineurotoxic $\left(E C_{50, \tau}=0.96 \mathrm{mM}\right)$ than hydroxyectoine $\left(E C_{50, \tau}=2.20 \mathrm{mM}\right)$.

Inhibition of apomyoglobin fibrils formation by trehalose The effect of trehalose on the apomyoglobin aggregation kinetics was also studied using model (1), and excellent statistical results were obtained from the modeling and the description of the experimental data (Figure 4D and 

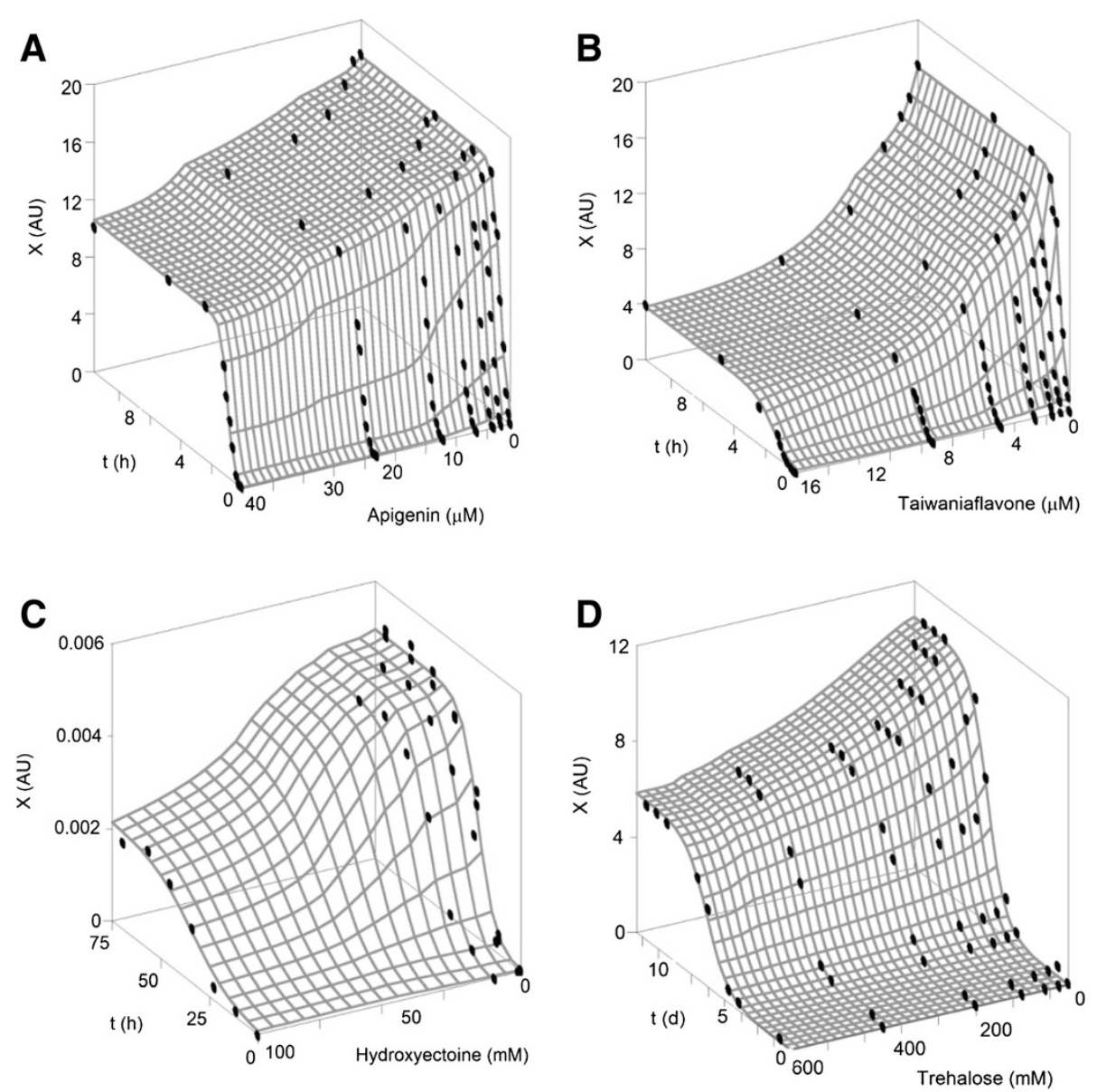

Figure 4 Amyloid protein aggregation kinetics at different concentrations of apigenin, ectoine, taiwaniaflavone and trehalose (points) and fittings to equation (1) (surface). $X$ : aggregation data measured by ThT fluorescence intensity at $482 \mathrm{~nm}$ or $490 \mathrm{~nm}$ (AU). A: experimental data of apigenin. B: taiwaniaflavone data. C: experimental data of hydroxyectoine. D: data of trehalose affecting apomyoglobin kinetics.

Table 4). As in the previous case, the disaccharide significantly inhibited the two kinetic parameters $v_{m}$ and $X_{m}$ without affecting the pre-nucleation phase $(\lambda)$. Nevertheless, its relative efficacy was obtained at a much higher concentration (21.43 mM), and much longer times $(6.5 \mathrm{~d})$ were required than compared with the other cases studied.

\section{Conclusions}

In summary, a general bivariate model that combines the logistic equation for the description of kinetics and the Weibull equation for the chemical-concentration response has been proposed for the characterization of the inhibitory effects produced by several chemicals on the growth of the aggregation of amyloid proteins. In all cases, the inhibitory effects on the kinetic parameters were established, and the theoretical response surfaces were in perfect agreement with the selected data. In addition, the recent definition of true and apparent inhibitors reported by Martins [24] can be also evaluated and validated. EGCG at $\mathrm{pH} 7.4$ and a temperature of $37^{\circ} \mathrm{C}$ was the best option for the reduction of the formation of insulin fibrils $\left(E C_{50, \tau}=6 \mu \mathrm{M}\right)$ but the shortest time $(\tau)$ was obtained with methylglyoxal. For the A $\beta 42$ amyloid protein, the biflavonoid taiwaniaflavone produced the highest inhibition response at the lowest dose $(0.91 \mu \mathrm{M})$ and the shortest time $(0.65 \mathrm{~h})$. The bivariate equation was validated using data obtained by two methods based on different chemical phenomena. Although this model can not define the mechanisms of action of chemical inhibitors on protein aggregation, it provides a consistent tool for the comparison of the ability of such compounds in the inhibition of the protein fibrillation process, regardless of the method used for its determination, and is a first step for the optimization of the in vitro application of them. Further experiments and corresponding modeling should be done to establish its validity for in vivo applications of anti-aggregation chemicals. 
Table 4 Parametric estimates and confidence intervals $(\alpha=0.05)$ from the equation $(1)$ applied to the aggregation of Aß42-amyloid protein increased data influenced by apigenin, ectoine, hidroxyectoine and taiwaniaflavone concentrations

\begin{tabular}{|c|c|c|c|c|c|c|}
\hline \multicolumn{2}{|l|}{ Parameters } & \multirow{2}{*}{$\begin{array}{l}\text { Apigenin } \\
17.43 \pm 0.50\end{array}$} & \multirow{2}{*}{$\begin{array}{c}\text { Ectoine } \\
(5.07 \pm 0.23) \times 10^{-3}\end{array}$} & \multirow{2}{*}{$\begin{array}{c}\text { Hidroxyectoine } \\
(4.96 \pm 0.24) \times 10^{-3}\end{array}$} & \multirow{2}{*}{$\begin{array}{c}\text { Taiwaniaflavone } \\
16.55 \pm 0.55\end{array}$} & \multirow{2}{*}{$\begin{array}{r}\text { Trehalose } \\
10.49 \pm 0.28\end{array}$} \\
\hline Aggregation model & $X_{m}(\mathrm{AU})$ & & & & & \\
\hline & $v_{m}\left(\mathrm{AU} \mathrm{h}^{-1}\right.$ or $\left.\mathrm{AU} \mathrm{d}^{-1}\right)$ & $16.10 \pm 1.49$ & $(0.24 \pm 0.05) \times 10^{-3}$ & $(0.30 \pm 0.08) \times 10^{-3}$ & $17.01 \pm 2.09$ & $3.31 \pm 0.33$ \\
\hline & $\lambda(h$ or $d)$ & $0.25 \pm 0.03$ & $11.60 \pm 2.26$ & $13.50 \pm 2.31$ & $0.27 \pm 0.06$ & $5.76 \pm 0.14$ \\
\hline \multirow[t]{3}{*}{ Effect on $X_{m}$} & $K_{x}$ & $0.41 \pm 0.06$ & $1.00 \pm 0.99$ & $1.00 \pm 0.90$ & $0.78 \pm 0.05$ & $0.44 \pm 0.03$ \\
\hline & $m_{x}(\mathrm{mM}$ or $\mu \mathrm{M})$ & $6.52 \pm 1.93$ & $11.82 \pm 11.03$ & $66.70 \pm 65.78$ & $2.32 \pm 0.38$ & $51.58 \pm 7.27$ \\
\hline & $a_{x}$ & $0.91 \pm 0.25$ & $0.19 \pm 0.13$ & $0.43 \pm 0.43$ & $0.98 \pm 0.16$ & $1.36 \pm 0.31$ \\
\hline \multirow[t]{3}{*}{ Effect on $v_{m}$} & $K_{v}$ & $0.38 \pm 0.12$ & $0.83 \pm 0.06$ & $0.86 \pm 0.16$ & $1.14 \pm 0.60$ & $0.53 \pm 0.08$ \\
\hline & $m_{v}(\mathrm{mM}$ or $\mu \mathrm{M})$ & $9.29 \pm 5.35$ & $0.33 \pm 0.32$ & 1.35 (NS) & $1.88 \pm 1.73$ & $33.22 \pm 17.26$ \\
\hline & $a_{v}$ & $1.35 \pm 1.13$ & $0.36 \pm 0.14$ & $0.34 \pm 0.20$ & $0.40 \pm 0.21$ & $0.66 \pm 0.33$ \\
\hline \multirow[t]{9}{*}{ Effect on $\lambda$} & $K_{\lambda}$ & $1.76 \pm 0.70$ & NS & NS & $1.27 \pm 1.13$ & NS \\
\hline & $m_{\lambda}(\mathrm{mM}$ or $\mu \mathrm{M})$ & $2.16 \pm 0.29$ & NS & NS & $2.53 \pm 1.45$ & NS \\
\hline & $a_{\lambda}$ & $2.39 \pm 0.99$ & NS & NS & $2.33 \pm 2.31$ & NS \\
\hline & $E C_{50, \tau}(\mathrm{mM}$ or $\mu \mathrm{M})$ & 2.45 & 0.96 & 2.20 & 0.91 & 21.43 \\
\hline & $\tau($ h or $d)$ & 0.75 & 17.31 & 20.52 & 0.65 & 6.54 \\
\hline & $p$-value & $<0.001$ & $<0.001$ & $<0.001$ & $<0.001$ & $<0.001$ \\
\hline & $B_{f}$ & 0.99 & 1.04 & 1.00 & 1.02 & 1.03 \\
\hline & $A_{f}$ & 1.06 & 1.09 & 1.18 & 1.11 & 1.08 \\
\hline & $R_{a d j}^{2}$ & 0.995 & 0.988 & 0.984 & 0.990 & 0.995 \\
\hline
\end{tabular}

The case of apomyoglobin affected by trehalose is also shown. Statistical values of adjusted coefficient of multiple determination $\left(R_{a d j}^{2}\right)$ and $p$-values from Fisher's F-test $(a=0.05) . B_{f}$ and $A_{f}$ are the bias and accuracy factor, respectively. NS: non-significant.

\section{Appendix}

\section{Reparameterization of logistic equation}

It is well-known the autocatalytic origin of the logistic equation based on the following differential equation:

$$
\frac{d X}{d t}=k_{a p p} X\left(1-\frac{X}{X_{m}}\right)
$$

which, integrated between $X_{0} \rightarrow X$ and $0 \rightarrow t$ gives the explicit form of aggregation growth as a function of the time:

$$
X=\frac{X_{m}}{1+\exp \left[\ln \left(\frac{X_{m}-X_{0}}{X_{0}}\right)-k_{a p p} t\right]}
$$

The parameter $\tau$ is defined as the time required to obtain the semimaximum fibrillation growth (when $X=X_{m} / 2$ ):

$$
\frac{X_{m}}{2}=\frac{X_{m}}{1+\left(\frac{X_{m}-X_{0}}{X_{0}}\right) \exp \left[-k_{a p p} \tau\right]} \Rightarrow \tau=\frac{1}{k_{a p p}} \ln \left(\frac{X_{m}-X_{0}}{X_{0}}\right)
$$

The inflection point $\left(t=t_{i}\right)$ can be obtained when the second derivative from (A.1) is equal to zero and the abscissa is isolated [31]:

$$
t_{i}=\tau=\frac{1}{k_{a p p}} \ln \left(\frac{X_{m}-X_{0}}{X_{0}}\right)
$$

The value of aggregation when $t=t_{i}$ is:

$$
X\left(t_{i}\right)=\frac{X_{m}}{2}
$$

The slope in the inflection point $\left(v_{m}\right)$ is defined by the following operation:

$$
\begin{aligned}
v_{m}=\left.\frac{d X}{d t}\right|_{t=t_{i}} & =\frac{X_{m} k_{a p p} \exp \left[\ln \left(\frac{X_{m}-X_{0}}{X_{0}}\right)-k_{a p p} t_{i}\right]}{\left[1+\exp \left[\ln \left(\frac{X_{m}-X_{0}}{X_{0}}\right)-k_{a p p} t_{i}\right]\right]^{2}} \\
& =\frac{X_{m} k_{a p p}}{4}
\end{aligned}
$$

The lag phase $(\lambda)$ or pre-nucleation phase is defined as the intersection of the tangent at the inflection point with the abscissa (Figure 1):

$$
R=X\left(t_{i}\right)+v_{m}\left(L-t_{i}\right)
$$

with $L=\lambda$ when $R=0$ : 


$$
\lambda=t_{i}-\frac{X\left(t_{i}\right)}{v_{m}}=\tau-\frac{X_{m}}{2 v_{m}}=\tau-\frac{2}{k_{a p p}}
$$

Reorganizing terms, two reparameterized functions can be defined:

$$
\begin{aligned}
& X=\frac{X_{m}}{1+\exp \left[2+\frac{4 v_{m}}{X_{m}}(\lambda-t)\right]} \\
& X=\frac{X_{m}}{1+\exp \left[\frac{4 v_{m}}{X_{m}}(\tau-t)\right]}
\end{aligned}
$$

When parameters from both equations are influenced by chemical agent concentration, they can be rewritten as follows:

$$
\begin{aligned}
& X=\frac{X_{m \bullet}}{1+\exp \left[2+\frac{4 v_{m} \cdot}{X_{m}}(\lambda \cdot-t)\right]} \\
& X=\frac{X_{m \bullet}}{1+\exp \left[\frac{4 v_{m} \cdot}{X_{m}}(\tau \cdot-t)\right]}
\end{aligned}
$$

On the other hand, the calculation of the time $\tau$ for $E C_{50 \text {, }}$ is obtained by the following formula:

$$
\begin{aligned}
\frac{X_{m \bullet}}{4} & =\frac{X_{m \bullet}}{1+\exp \left[\frac{4 v_{m}}{X_{m}}(\tau \cdot-\tau)\right]} \Rightarrow \tau \\
& =\tau \cdot-\frac{X_{m \cdot} \ln 3}{4 v_{m}}
\end{aligned}
$$

\section{Weibull equation and bivariate model (1)}

The most interesting form of Weibull equation for dose-response modelling is expressed as follows [35]:

$$
Y=Y_{m}\left\{1-\exp \left[-\ln 2\left(\frac{C}{m}\right)^{a}\right]\right\}
$$

where, $Y$ is the response and $Y_{m}$ the maximum response, $m$ is the concentration corresponding to the semi-maximum response, $C$ is the concentration and $a$ is a shape parameter related to the maximum slope of the response.

This equation can be modified according with the graphical tendencies of chemicals effects (Figure 1) on the aggregation parameters [38]:

$$
\theta=\theta_{0}\left(1-Y_{\theta}\right) \quad \text { or } \quad \theta=\theta_{0}\left(1+Y_{\theta}\right)
$$

Thus, decrease of $\nu_{m}$ and $X_{m}$ and increase of $\lambda$ and $\tau$ were the characteristic responses observed for the inhibition of amyloid protein fibrillation kinetics induced by chemicals:

$$
\begin{aligned}
& X_{m \cdot}=X_{m}\left\{1-K_{x}\left[1-\exp \left(-\ln 2\left(\frac{C}{m_{x}}\right)^{a_{x}}\right)\right]\right\} \\
& v_{m}=v_{m}\left\{1-K_{v}\left[1-\exp \left(-\ln 2\left(\frac{C}{m_{v}}\right)^{a_{\nu}}\right)\right]\right\} \\
& \lambda \cdot=\lambda\left\{1+K_{\lambda}\left[1-\exp \left(-\ln 2\left(\frac{C}{m_{\lambda}}\right)^{a_{\lambda}}\right)\right]\right\} \\
& \tau \cdot=\tau\left\{1+K_{\tau}\left[1-\exp \left(-\ln 2\left(\frac{C}{m_{\tau}}\right)^{a_{\tau}}\right)\right]\right\}
\end{aligned}
$$

When the equations (A.15) are inserting directly on equation (A.10) or (A.11), the bivariate model (1) is obtained.

\section{Additional file}

Additional file 1: Excel spreadsheet used for modeling the Ab42amyloid apigenin case.

\section{Competing interests}

The author declares that he has no competing interests.

\section{Acknowledgements}

The authors also thank the Unit of Information Resources for Research (URICI-CSIC) for the co-financing of this publication in Open Access.

Received: 24 May 2013 Accepted: 14 February 2014

Published: 27 February 2014

\section{References}

1. Bucciantini M, Giannoni E, Chiti F, Baroni F, Formigli L, Zurdo J, Taddei N, Ramponi G, Dobson CM, Stefani M: Inherent toxicity of aggregates implies a common mechanism for protein misfolding diseases. Nature 2002, 416:507-511.

2. Chiti F, Dobson CM: Protein misfolding, functional amyloid, and human disease. Annu Rev Biochem 2006, 75:333-366.

3. Stefani M, Dobson CM: Protein aggregation and aggregate toxicity: new insights into protein folding, misfolding diseases, and biological evolution. J Mol Med 2003, 81:678-699.

4. Uversky VN, Fink AL: Conformational constraints for amyloid fibrillation: the importance of being unfolded. Biochim Biophys Acta 2004, 1698:131-153.

5. Wang SSS, Good TA: An overview of Alzheimer's disease. J Chin Inst Chem Eng 2005, 36:533-559.

6. Cromwell MEM, Hilario E, Jacobson F: Protein aggregation and bioprocessing. AAPS J 2006, 8:E572-E579.

7. Rosenberg AS: Effects of protein aggregates: an immunologic perspective. AAPS J 2006, 8:E501-E507.

8. Knowles TP, Fitzptrick AW, Meehan S, Mott HR, Vendruscolo M, Dobson CM, Welland ME: Role of intermolecular forces in defining material properties of protein nanofibrils. Science 2007, 318:1900-1903.

9. Nelson R, Eisenberg D: Recent atomic models of amyloid fibril structure. Curr Opin Struct Biol 2006, 16:260-265.

10. Ross CA, Poirier MA: What is the role of protein aggregation in neurodegeneration? Nat Rev Mol Cell Biol 2005, 6:891-898.

11. Mauro M, Craparo EF, Podesta A, Bulone D, Carrotta R, Martorana V, Tiana G, San Biagio PL: Kinetics of different processes in human insulin amyloid formation. J Mol Biol 2007, 366:258-274

12. Loksztejn A, Dzwolak W: Vortex-induced formation of insulin amyloid superstructures probed by time-lapse atomic force microscopy and circular dichroism spectroscopy. J Mol Biol 2010, 395:643-655.

13. Slusky V, Tamada JA, Klibanov AM, Langer R: Kinetics of insulin aggregation in aqueous solutions upon agitation in the presence of hydrophobic surfaces. Proc Natl Acad Sci U S A 1991, 88:9377-9381.

14. Dische FE, Wernstedt C, Westermark GT, Westermark P, Pepys MB, Rennie JA, Gilbey SG, Watkins PJ: Insulin as an amyloid-fibril protein at sites of repeated insulin injections in a diabetic patient. Diabeto/ 1988, 31:158-161. 
15. Kanapathipillaia M, Lentzenb G, Sierksa M, Parka CB: Ectoine and hydroxyectoine inhibit aggregation and neurotoxicity of Alzheimer's $\beta$-amyloid. FEBS Lett 2005, 579:4775-4780

16. Thapa A, Woo ER, Chi EY, Sharoar MG, Jin HG, Shin SY, Park IS: Biflavonoids are superior to monoflavonoids in inhibiting amyloid- $\beta$ toxicity and fibrillogenesis via accumulation of nontoxic oligomer-like structures. Biochem 2011, 50:2445-2455.

17. Andrews JM, Roberts CJ: A Lumry-Eyring nucleated polymerization model of protein aggregation kinetics: 1. Aggregation with pre-equilibrated unfolding. J Phys Chem B 2007, 111:7897-7913.

18. Bernacki J, Murphy RM: Model discrimination and mechanistic interpretation of kinetic data in protein aggregation studies. Biophys $J$ 2009, 96:2871-2887.

19. Ghosh P, Kumar A, Datta B, Rangacharim V: Dynamics of protofibril elongation and association involved in $A \beta 42$ peptide aggregation in Alzheimer's disease. BMC Bioinformatics 2010, 11(Suppl 6):S24.

20. Lee CC, Nayak A, Sethuraman A, Belfort G, McRae GJ: A three-stage kinetic model of amyloid fibrillation. Biophys J 2007, 92:3448-3458.

21. Roberts $\mathrm{CJ}$ : Kinetics of irreversible protein aggregation: Analysis of extended Lumry-Eyring models and implications for predicting protein shelf life. J Phys Chem B 2003, 107:1194-1207.

22. Ruzafa D, Conejero-Lara F, Morel B: Modulation of the stability of amyloidogenic precursors by anion binding strongly influences the rate of amyloid nucleation. Phys Chem Chem Phys 2013, 15:15508-15517.

23. Ruzafa D, Morel B, Varela L, Azuaga Al, Conejero-Lara F: Characterization of oligomers of heterogeneous size as precursors of amyloid fibril nucleation of an $\mathrm{SH} 3$ domain: an experimental kinetics study. Plos One 2012, 7:e49690.

24. Morris AM, Watzky MA, Finke RG: Protein aggregation kinetics, mechanism, and curve-fitting: a review of the literature. Biochim Biophys Acta 2009, 1794:375-397.

25. Crespo R, Rocha FA, Damas AM, Martins PM: A generic crystallization-like model that describes the kinetics of amyloid fibril formation. J Biol Chem 2012, 287:30585-30594.

26. Martins PM: True and apparent inhibition of amyloid fibril formation. Prion 2013, 7:136-139.

27. Morris AM, Watzky MA, Agar JN, Finke RG: Fitting neurological protein aggregation kinetic data via a 2-step, minimal/"Ockham's Razor" model: the Finke-Watzky mechanism of nucleation followed by autocatalytic surface growth. Biochem 2008, 47:2413-2427.

28. Morris AM, Finke RG: $a$-Synuclein aggregation variable temperature and variable $\mathrm{pH}$ kinetic data: a re-analysis using the Finke-Watzky 2-step model of nucleation and autocatalytic growth. Biophys Chem 2009, 140:9-15.

29. Naiki H, Hasegawa K, Yamaguchi I, Nakamura H, Gejyo F, Nakakuki K: Apolipoprotein $E$ and antioxidants have different mechanisms of inhibiting Alzheimer's $\beta$-Amyloid fibril formation in vitro. Biochem 1998, 37:17882-17889

30. Nielsen L, Khurana R, Coats A, Frokjaer S, Brange J, Vyas S, Uversky VN, Fink AL: Effect of environmental factors on the kinetics of insulin fibril formation: elucidation of the molecular mechanism. Biochem 2001, 40:6036-6046

31. Wang SH, Dong XY, Sun Y: Effect of (-)-epigallocatechin-3-gallate on human insulin fibrillation/aggregation kinetics. Biochem Eng J 2012, 63:38-49.

32. Oliveira LMA, Lages A, Gomes RA, Neves H, Família C, Coelho AV, Quintas A: Insulin glycation by methylglyoxal results in native-like aggregation and inhibition of fibril formation. BMC Biochem 2011, 12:41.

33. Wang SSS, Liu KN, Han TC: Amyloid fibrillation and cytotoxicity of insulin are inhibited by the amphiphilic surfactants. Biochim Biophys Acta 2010, 1802:519-530

34. Vilasi S, lannuzzi C, Portaccio M, Irace G, Sirangelo I: Effect of trehalose on W7FW14F apomyoglobin and insulin fibrillization: new insight into inhibition activity. Biochem 2008, 47:1789-1796.

35. Murado MA, Vázquez JA, Rial D, Beiras R: Dose-response modeling with two agents: application to the bioassay of oil and shoreline cleaning agents. J Hazardous Materials 2011, 185:807-817.

36. Riobó P, Paz B, Franco JM, Vázquez JA, Murado MA, Cacho E: Mouse bioassay for palytoxin. Specific symptoms and dose-response against dose-death time relationships. Food Chem Toxicol 2008, 46:2639-2647.
37. Vázquez JA, Murado MA: Mathematical tools for objective comparison of microbial cultures Application to evaluation of 15 peptones for lactic acid bacteria productions. Biochem Eng J 2008, 39:276-287.

38. Rial D, Vázquez JA, Murado MA: Effects of three heavy metals on the bacteria growth kinetics: a bivariate model for toxicological assessment. Appl Microbiol Biotechnol 2011, 90:1095-1109.

39. Vázquez JA, Durán A, Rodríguez-Amado I, Prieto MA, Rial D, Murado MA: Evaluation of toxic effects of several carboxylic acids on bacterial growth by toxicodynamic modelling. Microb Cell Fact 2011, 10:100.

40. Ross T: Indices for performance evaluation of predictive models in food microbiology. J Appl Bacteriol 1996, 81:501-508.

41. Vázquez JA, Murado MA: Unstructured mathematical model for biomass, lactic acid and bacteriocin production by lactic acid bacteria in batch fermentation. J Chem Technol Biotechnol 2008, 83:91-96.

42. Sabaté $R$, Villar-Piqué $A$, Espargaró $A$, Ventura S: Temperature dependence of the aggregation kinetics of Sup35 and Ure2p yeast prions. Biomacromolecules 2012, 13:474-483.

43. Fändrich $\mathrm{M}$ : Absolute correlation between lag time and growth rate in the spontaneous formation of several amyloid-like aggregates and fibrils. J Mol Biol 2007, 365:1266-1270.

44. Vázquez JA, Lorenzo JM, Fuciños P, Franco D: Evaluation of non-linear equations to model different animal growths with mono and bisigmoid profiles. J Theor Biol 2012, 314:95-105

45. Murado MA, González MP, Vázquez JA: Dose-reponse relationships. An overview a generative model and its application to the verification of descriptive models. Enz Microb Technol 2002, 31:439-455.

46. Riobó P, Paz B, Franco JM, Vázquez JA, Murado MA: Proposal for a simple and sensitive haemolytic assay for palytoxin. Toxicological dynamics, kinetics, ouabain inhibition and thermal stability. Harmful Algae 2008, 7:415-429.

47. Shimanouchi T, Onishi R, Kitaura N, Umakoshi H, Kuboi R: Copper-mediated growth of amyloid $\beta$ fibrils in the presence of oxidized and negatively charged liposomes. J Biosc Bioeng 2011, 112:611-615.

48. Wang SSS, Chou SW, Liu KN, Wu CH: Effects of glutathione on amyloid fibrillation of hen egg-white lysozyme. Int J Biol Macromol 2009, 45:321-329.

49. Arora A, Ha C, Park CB: Inhibition of insulin amyloid formation by small stress molecules. FEBS Lett 2004, 564:121-125.

50. Vorob'eva LI: Stressors, stress reactions, and survival of bacteria: a review. Appl Biochem Microbiol 2004, 40:261-269.

doi:10.1186/2050-6511-15-9

Cite this article as: Vázquez: Modeling of chemical inhibition from amyloid protein aggregation kinetics. BMC Pharmacology and Toxicology 2014 15:9.

\section{Submit your next manuscript to BioMed Central and take full advantage of:}

- Convenient online submission

- Thorough peer review

- No space constraints or color figure charges

- Immediate publication on acceptance

- Inclusion in PubMed, CAS, Scopus and Google Scholar

- Research which is freely available for redistribution 